\title{
Empenamento, níveis hormonais de triiodotironina e tiroxina e temperatura corporal de frangos de corte de diferentes genótipos criados em diferentes condições de temperatura
}

\author{
Feathering, triiodothyronine and thyroxine plasma levels and body temperature \\ of two broiler lines raised under different temperatures
}

\author{
Fabiano Dahlke ${ }^{1}$ Elisabeth Gonzales ${ }^{2}$ Adriano Cordeiro Gadelha ${ }^{3}$ \\ Alex Maiorka ${ }^{1}$ Sebastião Aparecido Borges ${ }^{4}$ Paulo Sérgio Rosa $^{5}$ \\ Daniel Emygdio Faria Filho ${ }^{5}$ Renato Luis Furlan ${ }^{6}$
}

\section{RESUMO}

Estudou-se o empenamento, os níveis hormonais de Triiodotironina $\left(T_{3}\right)$ e Tiroxina $\left(T_{4}\right)$ e a temperatura corporal de frangos criados em diferentes temperaturas. Foram alojados 180 pintainhos Cobb 500 e 180 pintainhos ISA Label JA57, em temperaturas termoneutra, quente ou fria. $O$ delineamento utilizado foi inteiramente ao acaso, em modelo fatorial $2 \times 3$ (2 linhagens e 3 temperaturas) com 8 repetições. Houve um aumento das concentrações de $T_{3}$, nas aves criadas no frio, $e$ uma redução no calor. Também no calor, os frangos ISA Label apresentaram níveis mais altos de $T_{4}$ As aves Cobb apresentaram uma redução de $T_{4}$ no calor ou nó frio aos 42 dias e no calor aos 21 dias de idade. Houve menor empenamento aos 42 dias, quando os frangos foram criados em alta temperatura e um menor empenamento das aves ISA Label, quando comparadas aos frangos Cobb. As aves criadas no calor apresentaram maior temperatura corporal. Os frangos Cobb apresentaram um aumento na sua temperatura interna, quando criados em ambiente quente. Já os frangos da linhagem ISA Label mantiveram sua temperatura interna, independentemente da temperatura ambiente. É possível concluir que a temperatura ambiente afeta o empenamento dos frangos de corte de linhagens de rápido ganho de peso, que também apresentaram menor tolerância ao calor, demonstrada através de uma maior temperatura corporal e temperatura interna.

Palavras-chave: empenamento, frangos de corte, temperatura ambiente, tiroxina $e$ triiodotironina.

\section{ABSTRACT}

Feather growth, plasmatic levels of $T_{3}$ and $T_{4}$ and body temperature were evaluated in broiler raised under different temperatures. The two evaluated broiler lines were Cobb-500 and ISA-Label JA57. One hundred and eighty birds of each line were raised under cold, neutral or hot temperatures in a complete randomized design with $3 \times 2$ factorial scheme (3 temperatures and 2 lines), with 8 repetitions. There was a significant increase in $T_{3}$ levels of birds raised under cold temperature but, under hot temperature, these levels decresed. Under high temperatures, ISA Label birds showed the higest levels of $T_{4}$ The Cobb birds showed significant $T_{4}$ decrease under both, cold and hot temperatures, at 42 days of age; and at 21 days of age this decrease was observed only under hot temperature. There was lower feathering at 42 days of age when birds were raised under hot temperature. ISA Label broilers had a better feather growth than those of Cobb line. Birds raised in a hot environment had higher temperature. Cobb broilers had a significant increase in internal temperature when raised under hot conditions. However ISA Label broilers maintained their body and internal temperature, independently of the raising temperature. It was concluded that environmental temperature affects feathering of broiler chickens from lines selected for fast body weight gain, which also showed low heat tolerance, demonstrated by the higher body and internal temperatures.

Key words: broiler chickens, environmental temperature, feathering, triiodothyronine and thyroxine.

${ }^{1}$ Professor Doutor, Departamento de Zootecnia, Setor de Ciências Agrárias, Universidade Federal do Paraná, Rua dos Funcioná rios, 1540, 80035-050, Curitiba, PR, Brasil. E-mail: fdahlke@ufpr.br

${ }^{2}$ Doutor, Faculdade de Veterinária e Zootecnia, Universidade Estadual Paulista (UNESP), Botucatu, SP, Brasil.

${ }^{3}$ Professor Doutor, Faculdade de Medicina Veterinária, Universidade Estadual do Ceará, CE, Brasil.

${ }^{4}$ Professor Doutor, Faculdade de Medicina Veterinária, Universidades Tuiuti do Paraná, PR, Brasil.

${ }^{5}$ Doutorando, Faculdade de Ciências Agrárias e Veterinárias (FCAV), UNESP, Jaboticabal, SP, Brasil.

${ }^{6}$ Professor, Doutor, FCAV, Unesp, Jaboticabal, SP, Brasil. 


\section{INTRODUÇÃO}

As condições climáticas das regiões tropicais (alta temperatura e umidade) têm interferido negativamente na produtividade e qualidade da criação de frangos de corte sendo que as linhagens com alta taxa de crescimento são as que apresentam maior sensibilidade (CAHANER et al., 1995). Neste sentido, além dos estudos das condições ambientais e nutricionais (FARIA FILHO, 2003), alguns trabalhos foram realizados na área de genética, através da introgressão do gene pescoço pelado $(\mathrm{Na})$ em linhagens de frangos de corte para aumentar a resistência ao calor, devido ao fato de esse gene promover uma redução do empenamento, principalmente na região do pescoço, resultando em uma maior habilidade em dissipar calor através das áreas superficiais expostas (YAHAV et al., 1998; DEEB \& CAHANER, 1999).

Existe uma relação direta entre temperatura ambiental e empenamento, embora os dados não sejam conclusivos. YALÇIN et al. (1997) verificaram maior empenamento em aves criadas no verão. COELLO (2003) e WYLIE et al. (2001) não encontraram diferença do peso, comprimento e densidade das penas, em aves submetidas a temperaturas quente ou fria. Já COOPER \& WASHBURN (1998) verificaram que o empenamento foi reduzido quando as aves foram expostas a uma temperatura de $32^{\circ} \mathrm{C}$ até os 49 dias de idade e GERAERT et al. (1996) constataram que a redução no empenamento só é observada quando o período de exposição ao calor é maior que 14 dias. Em contra partida, EDENS et al. (2001) observaram melhora no empenamento em clima frio.

Embora a redução do empenamento possa facilitar a dissipação de calor em frangos criados em ambiente quente, uma boa cobertura de penas é necessária para a manutenção de uma boa qualidade de carcaça. Diversas lesões verificadas em frangos de corte, como calos de peito, arranhões, lacerações, cortes e outros traumas de pele, causados por uma má cobertura de penas resultam em condenação de carcaça nas linhas de abate (MENDES, 2001).

Os hormônios tireoideanos Tiiodotironina $\left(T_{3}\right)$ e Tiroxina $\left(T_{4}\right)$ têm sido considerados os mais importantes no controle dos processos metabólicos das aves, influenciando o crescimento e a eficiência alimentar, o consumo de oxigênio, a síntese e metabolismo de proteínas, carboidratos e lipídios; a termogênese e a composição corporal (LAWRENCE \& FOLLER, 1997). Desta forma, o presente estudo objetivou avaliar o efeito de diferentes temperaturas de criação sobre o empenamento, temperatura corporal e sobre os níveis dos hormônios tireoideanos $\left(\mathrm{T}_{3}\right.$ e $\left.\mathrm{T}_{4}\right)$ de frangos de corte de diferentes genótipos.

\section{MATERIAL E MÉTODOS}

Foram utilizados 360 frangos de corte de dois diferentes genótipos, sendo 180 aves da linhagem híbrida comercial Cobb 500, de rápido ganho de peso e 180 frangos ISA Label JA 57, de crescimento lento. As aves foram criadas de 1 a 42 dias em 3 câmaras climáticas, sob três condições de temperatura: Temperatura Termoneutra de acordo com a idade das aves ( 5 a 7 dias de idade: $32^{\circ} \mathrm{C}$; 8 a 14 dias de idade: $30^{\circ} \mathrm{C} ; 15$ a 21 dias de idade: $26^{\circ} \mathrm{C}$ e de 22 a 42 dias de idade: $24^{\circ} \mathrm{C}$ ); Temperatura Quente, com a temperatura variando de 3 a $9^{\circ} \mathrm{C}$ acima da temperatura neutra e Temperatura Fria com variações de 7 a $9^{\circ} \mathrm{C}$ abaixo da temperatura termoneutra.

Foram fornecidos dois tipos de ração durante o período experimental, uma inicial (1-21 dias) e outra de crescimento (22-42 dias), de acordo com as recomendações do NRC (1994). Aos 42 dias de idade foram selecionadas oito aves por tratamento para o estudo do padrão de empenamento, que consistiu na avaliação visual das aves, através de 4 avaliadores previamente treinados, classificando em escores de 0 a 5 (EDENS et al., 2001), de acordo com a densidade de empenamento e estágio de desenvolvimento das penas nas regiões: dorso (dorsopelvico), peito (pectoral + esternal), pernas (femural), abdômen (medial e lateral) e asa (umeral e cobertura marginal superior do prepatagium). Nos mesmos dias, foram coletados três $\mathrm{mL}$ de sangue de oito aves por tratamento, utilizandose seringas previamente heparinizadas. As amostras de sangue foram centrifugadas (2000rpm, por 10 minutos) e o plasma utilizado para determinar $\mathrm{T}_{3}$ e $\mathrm{T}_{4}$ através do procedimento de radoimunoensaio (RIA), com kits "Coat-a-count", através do contador de radiação gama C12 DPC.

Para a mensuração da temperatura superficial média (TSM), foram registradas as temperaturas ( $\mathrm{T}$ ) da asa, cabeça, canela e dorso através de um termômetro infravermelho modelo 300T. A TSM foi calculada da seguinte forma: $\operatorname{TSM}=(0,12$ Tasa $)+$ $(0,03$ Tcabeça $)+(0,15$ Tcanela $)+(0,70$ Tdorso $)$. A temperatura corporal foi obtida através da fórmula $\mathrm{TC}=(0,7 \mathrm{Tcloacal})+(0,3 \mathrm{TMS})$. Para a determinação da temperatura cloacal, foi utilizada uma sonda acoplada a um termômetro modelo TUC 46, de onde foi medida a temperatura.

O delineamento experimental utilizado para as mensurações acima descritas foi inteiramente casualizado decomposto em um modelo fatorial 3 x 2 
(temperaturas ambiente e linhagens), com 6 tratamentos e 8 repetições. Os dados foram submetidos à análise de variância através do procedimento General

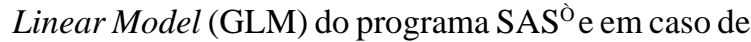
diferença estatística significativa, as médias foram comparadas pelo teste de Tukey a 5\% de probabilidade.

\section{RESULTADOS E DISCUSSÃO}

Na tabela 1, pode ser observado um aumento significativo nas concentrações plasmáticas de $T_{3}$, aos 21, 35 e 42 dias de idade, nas aves criadas em temperatura fria. A condição de alta temperatura de criação, por sua vez, reduziu a concentração dos níveis desse hormônio aos 21 e 42 dias de idade. Quando comparadas as linhagens, nota-se maiores níveis de T3 nos frangos ISA Label JA 57 aos 42 dias de idade.

Foi verificada interação significativa entre temperatura de criação e linhagem para as concentrações plasmáticas do hormônio tireoideano Tiroxina $\left(\mathrm{T}_{4}\right)$, aos 35 e 42 dias de idade (Tabela 1 ). Quando criados em temperatura quente, os frangos da linhagem ISA Label JA 57 apresentaram níveis significativamente mais altos de $\mathrm{T}_{4}$ que os frangos Cobb 500, nas duas idades. Já quando os frangos foram criados em temperatura termoneutra ou fria, houve maiores concentrações de $\mathrm{T}_{4}$ nas aves da linhagem Cobb 500.

Avaliando-se o efeito da temperatura individualmente em cada uma das linhagens, pode-se observar que as aves da linhagem Cobb 500 apresentaram uma redução significativa nos níveis plasmáticos de $\mathrm{T}_{4}$ quando criadas no calor, aos 35 dias, e, em condições de alta e baixa temperatura aos 42 dias de idade. Já as aves da linhagem ISA Label JA57 apresentaram um aumento no nível de T4 em baixa temperatura e um aumento ainda mais expressivo em alta temperatura, aos 21 dias de idade. Aos 42 dias,

Tabela 1 - Níveis plasmáticos de Tiroxina $\left(\mathrm{T}_{4}\right)$ e Triiodotironina $\left(\mathrm{T}_{3}\right)$ de frangos de corte da linhagem ISA Label JA 57 e Cobb 500 aos 21 , 35 e 42 dias de idade, criados em temperatura quente, termoneutra e fria e desdobramento das interações entre temperatura ambiente e linhagem, aos 35 e 42 dias de idade.

\begin{tabular}{|c|c|c|c|c|c|c|}
\hline & \multicolumn{3}{|c|}{$\mathrm{T}_{4}, \mathrm{ng} / \mathrm{mL}$} & \multicolumn{3}{|c|}{$\mathrm{T}_{3}, \mathrm{ng} / \mathrm{mL}$} \\
\hline & 21 dias & 35 dias & 42 dias & 21 dias & 35 dias & 42 dias \\
\hline \multicolumn{7}{|l|}{ Temperatura ambiente } \\
\hline Quente & 7,82 a & 7,81 & 5,50 & 0,63 c & $0,61 \mathrm{~b}$ & $0,58 \mathrm{c}$ \\
\hline Termoneutra & $6,37 \mathrm{~b}$ & 7,00 & 7,37 & $1,50 \mathrm{~b}$ & $0,63 \mathrm{~b}$ & $0,82 \mathrm{~b}$ \\
\hline Fria & $5,23 \mathrm{c}$ & 7,87 & 6,43 & $2,64 \mathrm{a}$ & $1,17 \mathrm{a}$ & 1,19 a \\
\hline \multicolumn{7}{|c|}{ Linhagem } \\
\hline Cobb 500 & $5,61 \mathrm{~b}$ & 7,95 & 6,99 & 1,46 & 0,82 & $0,77 \mathrm{~b}$ \\
\hline ISA Label JA 57 & $6,67 \mathrm{a}$ & 7,16 & 7,44 & 1,62 & 0,79 & $0,96 \mathrm{a}$ \\
\hline \multicolumn{7}{|c|}{ ANOVA, valores de P } \\
\hline $\begin{array}{l}\text { Temperatura ambiente } \\
\text { (TP) }\end{array}$ & 0,03 & 0,65 & 0,06 & 0,01 & 0,01 & 0,01 \\
\hline Linhagem (LI) & 0,04 & 0,63 & 0,21 & 0,40 & 0,59 & 0,05 \\
\hline TP $x$ LI & 0,15 & 0,04 & 0,01 & 0,08 & 0,63 & 0,94 \\
\hline CV\% & 21,65 & 20,32 & 22,15 & 27,18 & 25,82 & 26,15 \\
\hline \multicolumn{7}{|c|}{ Linhagem } \\
\hline & \multicolumn{4}{|c|}{ Cobb 500} & \multicolumn{2}{|c|}{ ISA Label JA 57} \\
\hline & \multicolumn{6}{|c|}{$\mathrm{T}_{4}(\mathrm{ng} / \mathrm{mL}) 35$ dias } \\
\hline Quente & \multicolumn{4}{|c|}{$7,00 \mathrm{~b} \mathrm{~B}$} & \multicolumn{2}{|c|}{8,62 а $A$} \\
\hline Termoneutra & \multicolumn{4}{|c|}{8,87 а $\mathrm{A}$} & \multicolumn{2}{|c|}{5,12 с В } \\
\hline \multirow[t]{2}{*}{ Fria } & \multicolumn{3}{|c|}{8,00 a $\mathrm{A}$} & & \multicolumn{2}{|c|}{ 7,75 b B } \\
\hline & \multicolumn{6}{|c|}{$\mathrm{T}_{4}(\mathrm{ng} / \mathrm{mL}) 42$ dias } \\
\hline Quente & \multicolumn{4}{|c|}{4,62 с В } & \multicolumn{2}{|c|}{7,37 a $A$} \\
\hline Termoneutra & \multicolumn{4}{|c|}{8,25 a $A$} & \multicolumn{2}{|c|}{ 6,75 b B } \\
\hline Fria & \multicolumn{4}{|c|}{$6,74 \mathrm{~b} \mathrm{~A}$} & \multicolumn{2}{|c|}{ 6,15 b B } \\
\hline
\end{tabular}

Médias seguidas de letras minúsculas distintas $(\mathrm{a}, \mathrm{b})$ na mesma coluna diferem entre si pelo teste de Tukey $(\mathrm{P}<0,05)$.

Médias seguidas de letras maiúsculas distintas $(\mathrm{A}, \mathrm{B})$ na mesma linha diferem entre si pelo teste de Tukey $(\mathrm{P}<0,05)$. 
frangos ISA Label JA 57 tiveram reduzida a sua concentrção plasmática de $\mathrm{T}_{4}$, quando criados em alta temperautura ambiente.

Para impedir um aumento excessivo da temperatura corporal, os frangos diminuem a produção do calor endógeno através de mecanismos físicos, comportamentais e endócrinos (YAHAV et al., 1996). O pricipal mecanismo endócrino é a diminuição dos hormônios tireoideanos circulantes, particularmente o $\mathrm{T}_{3}$, a forma metabolicamente ativa dos hormônios da tireóide, conhecido pela sua ação termogênica. Desta forma, a atividade da tireóide parece tornar-se menor com o aumento da temperatura ambiente e as aves apresentam maior tolerância ao calor quando há diminuição nos níveis circulantes de hormônios tireoideanos (ETCHES et al., 1995).

Aos 42 dias de idade (Tabela 2), foi verificada interação significativa entre temperatura ambiente e linhagem para empenamento total e empenamento no dorso. Estudando o efeito das temperaturas individualmente nas duas linhagens foi verificado que, quando os frangos da linhagem Cobb 500 foram criados em ambiente quente, apresentaram uma redução no empenamento total e empenamento da região do dorso. Já os frangos da linhagem ISA Label JA 57 mantiveram inalterado o empenamento em função da temperatura ambiental. Na região dorsal (Dorso), os frangos ISA Label JA 57 apresentaram maior cobertura de penas que os frangos Cobb 500, quando criados em ambiente quente. Na avaliação do empenamento total, foi constatado melhor empenamento para os frangos ISA Label JA 57 nas 3 temperaturas estudadas.

Nas demais regiões (perna, abdômen, asa e peito), com exceção da asa, os frangos Cobb 500 apresentaram melhor empenamento do que os frangos ISA Label JA 57. Independentemente da linhagem, houve uma redução no empenamento nas regiões do abdômen, asa e peito, quando os frangos foram criados em ambiente quente.

Além do efeito termogênico, os hormônios tireoideanos, especialmente o $\mathrm{T}_{3}$, atuam no controle dos mais diversos processos metabólicos das aves, como no crescimento (LUGER et al., 2001), no metabolismo, através de um maior consumo de oxigênio e ativação da síntese e metabolismo de proteínas, carboidratos e lipídios (LAWRENCE \& FOLLER, 1997) e absorção dos nutrientes (SZABO et al., 1989). Desta forma, a redução no empenamento, verificada em condição de alta temperatura, pode estar diretamente relacionada à redução nos níveis plasmáticos de $\mathrm{T}_{3}$, também verificada nessa condição adversa.

Segundo YAHAV et al. (1996), o frango de corte sofre com altas temperaturas porque a sua

Tabela 2 - Escore de empenamento de frangos de corte da linhagem Cobb 500 e ISA Label JA 57, criados em ambiente quente, termoneutro ou frio, aos 42 dias de idade e desdobramento da interação entre linhagem e temperatura na região do dorso e empenamento total aos 42 dias de idade.

\begin{tabular}{|c|c|c|c|c|c|c|}
\hline Temperatura ambiente & Perna & Abdomen & Dorso & Asa & Peito & Total \\
\hline Quente & 3,67 & $3,48 \mathrm{~b}$ & 3,75 & $4,07 \mathrm{~b}$ & $3,76 \mathrm{~b}$ & 3,22 \\
\hline Termoneutra & 3,71 & $3,70 \mathrm{~b}$ & 4,00 & $4,28 \mathrm{a}$ & $4,06 \mathrm{a}$ & 3,54 \\
\hline Fria & 3,82 & $4,01 \mathrm{a}$ & 4,06 & 4,31 a & 4,17 a & 3,96 \\
\hline \multicolumn{7}{|l|}{ Linhagem (L) } \\
\hline Cobb 500 & $3,43 \mathrm{~b}$ & $3,35 \mathrm{~b}$ & 3,89 & 4,25 & $3,76 \mathrm{~b}$ & 3,60 \\
\hline Isa Label JÁ 57 & $4,04 \mathrm{a}$ & $4,11 \mathrm{a}$ & 3,97 & 4,19 & $4,23 \mathrm{a}$ & 4,02 \\
\hline \multicolumn{7}{|l|}{ ANOVA, valores de $\mathrm{P}$} \\
\hline Temperatura (TP) & 0,14 & 0,01 & 0,02 & 0,00 & 0,01 & 0,01 \\
\hline Linhagem (L) & 0,01 & 0,01 & 0,38 & 0,42 & 0,01 & 0,01 \\
\hline TP X L & 0,29 & 0,22 & 0,03 & 0,35 & 0,36 & 0,01 \\
\hline \multirow[t]{2}{*}{$\mathrm{CV}$} & 8,22 & 9,31 & 9,30 & 6,25 & 8,83 & 8,36 \\
\hline & & \multicolumn{5}{|c|}{ Linhagem } \\
\hline \multicolumn{2}{|l|}{ Temperatura ambiente } & \multicolumn{2}{|c|}{ Cobb 500} & & \multicolumn{2}{|c|}{ ISA Label JA 57} \\
\hline \multirow{5}{*}{$\begin{array}{l}\text { Quente } \\
\text { Termoneutra } \\
\text { Fria }\end{array}$} & & \multirow{2}{*}{\multicolumn{3}{|c|}{3,00 b B }} & \\
\hline & & & & & \multicolumn{2}{|c|}{ 3,62 A } \\
\hline & & \multicolumn{2}{|c|}{3,75 a } & & \multirow{2}{*}{\multicolumn{2}{|c|}{$\begin{array}{l}3,62 \\
3,75\end{array}$}} \\
\hline & & \multicolumn{2}{|c|}{$4,00 \mathrm{a}$} & & & \\
\hline & & \multirow{2}{*}{\multicolumn{3}{|c|}{ Total }} & \\
\hline Quente & & & & & & 3,98 A \\
\hline Termoneutra & & \multicolumn{2}{|c|}{3,47 a $B$} & & \multicolumn{2}{|c|}{$3,95 \mathrm{~A}$} \\
\hline Fria & & \multicolumn{2}{|c|}{3,52 a B } & & & \\
\hline
\end{tabular}

Médias seguidas de letras minúsculas distintas (a,b) na mesma coluna diferem entre si pelo teste de Tukey $(\mathrm{P}<0,05)$. Médias seguidas de letras maiúsculas distintas (A,B) na mesma linha diferem entre si pelo teste de Tukey $(\mathrm{P}<0,05)$. 
cobertura de penas impede a dissipação de calor, conduzindo a um aumento da temperatura corporal. Para impedir este aumento de temperatura, os frangos miniminizam a produção de calor endógeno através da redução da ingestão de alimento, resultando em diminuição de desempenho. Como existe um equilíbrio entre o desenvolvimento das diversas estruturas do animal (LAWRENCE \& FOLLER, 1997), a depressão no crescimento corporal pode vir acompanhada também por uma redução do crescimento das penas, como observado neste ensaio.

Assim, a redução do empenamento pode ser uma resposta adaptativa da ave para a manutenção da homeostase térmica, através de uma melhor dissipação de calor (WYLIE et al., 2001). Dados semelhantes aos obtidos neste ensaio foram encontrados por COOPER \& WASHBURN (1998), que verificaram uma redução no empenamento quando as aves foram expostas a uma temperatura de $32^{\circ} \mathrm{C}$ até os 49 dias de idade. GERAERT et al. (1996) sugeriram que a redução do empenamento acontece somente quando a ave é exposta ao calor por mais de duas semanas. Estes últimos autores utilizaram programa de alimentação pair feeding (equalização do consumo das aves de todos os tratamentos em função do consumo das aves alojadas em alta temperatura), o que descarta a possibilidade da redução do empenamento em função da redução da ingestão de ração.

Os frangos criados em ambiente quente apresentaram maiores temperaturas superficiais e temperatura superficial média (Tabela 3). Quando as linhagens foram comparadas, foi observada uma maior temperatura superficial para a cabeça e canela dos frangos da linhagem Cobb 500.

Houve interação significativa entre os fatores temperatura ambiente e linhagem para temperatura cloacal e temperatura corporal. Avaliando-se as temperaturas individualmente nas linhagens (Tabela 3), foi verificado que os frangos Cobb 500 apresentaram um aumento significativo na sua temperatura interna (temperatura cloacal), quando criados em ambiente quente. Já os frangos da linhagem ISA Label JA 57 mantiveram sua temperatura interna, independentemente da temperatura em que foram criados até os 42 dias de idade. Comparando-se as linhagens em cada temperatura, observa-se que, em ambiente quente, os frangos Cobb 500 tiveram uma maior temperatura cloacal que os frangos ISA Label JA 57. Nas demais temperaturas de criação (termoneutra e fria) não houve diferença entre as linhagens.

A avaliação da temperatura corporal, através do desdobramento da interação entre temperatura de criação e linhagem mostrou que os frangos Cobb 500 apresentaram um aumento na sua temperatura corporal quando expostos à alta temperatura e uma redução em condição de baixa temperatura. Os frangos ISA Label JA 57 apresentaram alteração de temperatura corporal somente na condição de frio. Comparando-se as linhagens em cada temperatura podemos verificar que os frangos Cobb 500 possuem maior temperatura corporal que os frangos ISA Label JA 57 em condição de calor. Nas demais temperaturas de criação, não houve diferença entre as linhagens.

A habilidade do animal de manter a sua temperatura mesmo com a variação da temperatura ambiente vai depender do balanço entre a produção de calor e dissipação de calor (YALÇIN et al., 1997). Segundo DEEB \& CAHANER (1999), o aumento de temperatura é maior em frangos de empenamento normal do que em frangos com pescoço pelado, portador do gene $\mathrm{Na}$, devido ao seu menor empenamento. Em altas temperaturas, a cobertura de pena está positivamente associada à temperatura corporal e, da mesma forma, negativamente correlacionada ao ganho de peso (CAHANER et al., 1995)

Os frangos ISA Label JA 57 mantiveram constante a sua temperatura cloacal independente da variação da temperatura ambiental. Este resultado demonstra uma maior eficiência dos frangos portadores do gene pescoço pelado na regulação da temperatura corporal e maior tolerância ao calor, como anteriormente demonstrado por WASHBURN et al. (1980) e DEEB \& CAHANER (1999) que verificaram que a tolerância ao calor de linhagens de frangos de corte selecionadas para rápido ganho de peso foi significativamente menor do que para as linhagens de lento crescimento.

O estresse térmico crônico ao qual foram submetidos os frangos das diferentes linhagens acarretou em marcantes alterações anatomofisiológicas. Durante o período final da fase de crescimento, os frangos de corte tentam manter a homeostase térmica através da perda de calor pela ofegação (evaporação) e, em menor escala, pela perda de calor sensível (radiação e convecção). Quando a alta temperatura se torna constante, geralmente são verificados quadros de desidratação (YAHAV et al., 1998). Em alguns casos a desidratação impede a eficiência do método evaporativo (MARDER \& ARAD, 1989) e o aumento da perda de calor sensível pode facilitar a termotolerância. Neste sentido, a redução do empenamento, verificada nos frangos de linhagem para rápido ganho de peso, torna-se um mecanismo utilizado para aumentar a eficiência nesta taxa de perda de calor (YAHAV et al., 1998). 
Tabela 3 - Temperatura da asa, dorso, cabeça, canela, temperatura média superficial (TMS), temperatura cloacal e temperatura corporal (TC) de frangos de corte da linhagem Cobb 500 e ISA Label JA 57, com 42 dias de idade, criados em temperatura quente, termoneutra e fria e desdobramento da interação entre linhagem e temperatura ambiente para a temperatura cloacal e temperatura corporal.

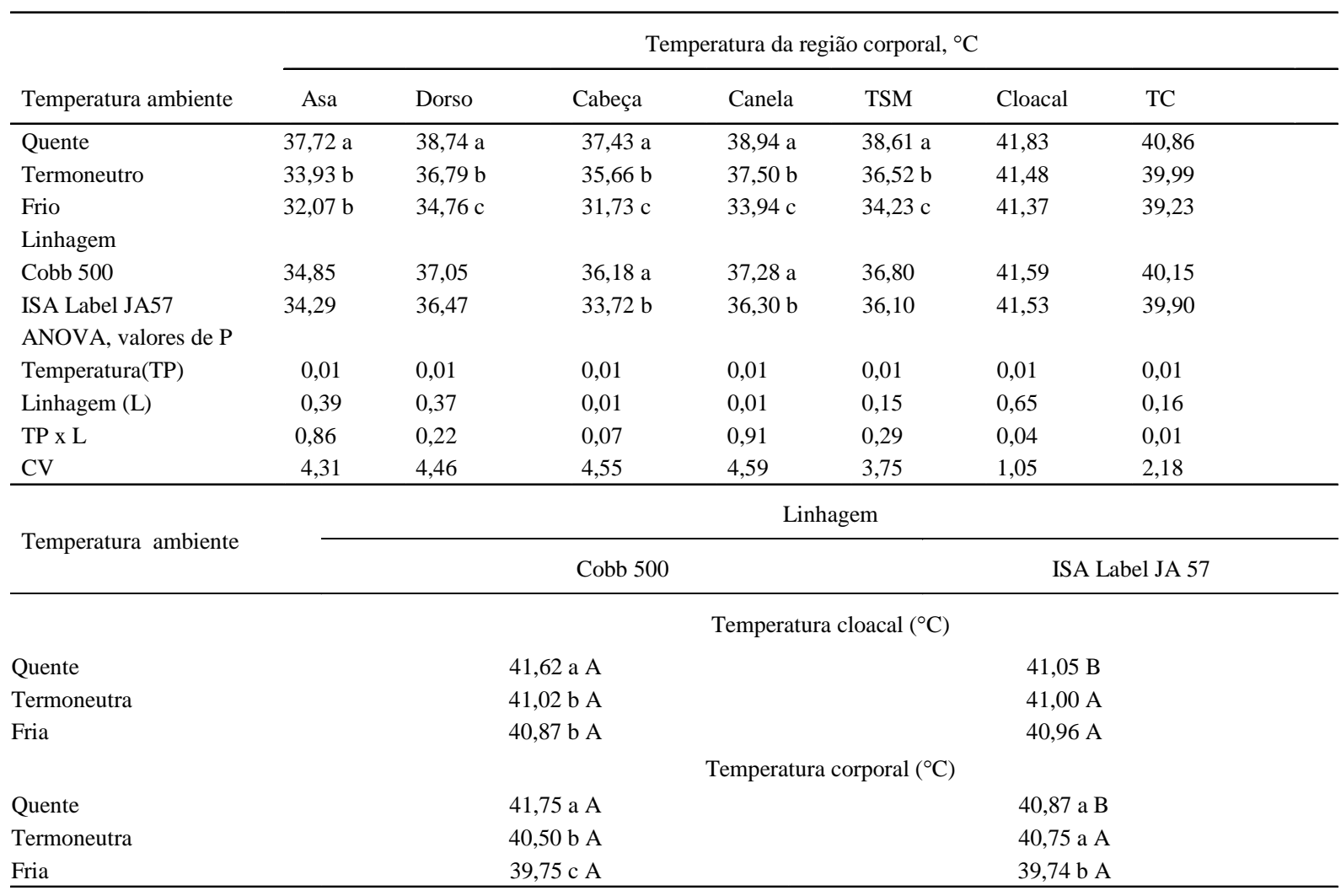

Médias seguidas de letras minúsculas distintas (a,b) na mesma coluna diferem entre si pelo teste de Tukey $(\mathrm{P}<0,05)$ Médias seguidas de letras maiúsculas distintas $(\mathrm{A}, \mathrm{B})$ na mesma linha diferem entre si pelo teste de Tukey $(\mathrm{P}<0,05)$

\section{CONCLUSÕES}

Os resultados obtidos neste estudo são indicativos de que a temperatura ambiente exerce efeito marcante no empenamento dos frangos de corte de linhagens de rápido ganho de peso. Frangos de linhagens comerciais de rápido crescimento apresentam menor tolerância ao calor, demonstrada através de uma maior temperatura corporal e interna, quando criados em ambiente quente. A temperatura ambiente inadequada altera os níveis plasmáticos de $\mathrm{T}_{3}$ e $\mathrm{T}_{4}$.

\section{REFERÊNCIAS BIBLIOGRÁFICAS}

CAHANER, A. et al. Effects of dietary protein under high ambient temperature on body weight, breast meat yield and abdominal fat deposition on broiler stock differing in growth rate and fatness. Poultry Science, Champaing, v.74, p.968975, 1995.

COELLO, C.L. Feathering: an experimental study. In: Feathering manual. Saint Louis : Novus ${ }^{\circledR}$ international, 2003. CD-ROM.
COOPER, M.A.; WASHBURN, K.W. The relationships of body temperature to weight gain, feed consumption and feed utilization in broiler under heat stress. Poultry Science, Champaing, v.77, p.237-242, 1998.

DEEB, N.; CAHANER, A. The effects of naked neck genotypes, ambient temperature, and feeding status and their interactions on body temperature and performance of broilers. Poultry Science, Champaing, v.78, p.1341-1346, 1999.

EDENS, F. et al. Housing and selenium influences on feathering in broilers. Journal of Applied Poultry Research, Mississippi, v.10, p.128-134, 2001.

ETCHES, R.J. et al. Behavioral, physiological, neuroendocrine and molecular responses to heat stress. In: ETCHES, R.J. et al. (ed). Poultry production in hot climates. Wallingford: CAB INTERNATIONAL, 1995. p.31-65.

FARIA FILHO, D.E. Efeito de dietas com baixo teor protéico, formuladas usando o conceito de proteína ideal, para frangos de corte criados em temperaturas fria, termoneutra e quente. 2003. 96f. Dissertação (Mestrado em Zootecnia) - Faculdade de Ciências Agrárias e Veterinárias, Universidade Estadual Paulista. 
GERAERT, P.A. et al. Metabolic and endocrine changes induced by chronic heat exposure in broiler chickens: growth performance, body composition and energy retention. British Poultry Science, London, v.75, p.195-204, 1996.

LAWRENCE, T.L.J.; FOWLER, V.R. Hormonal, genetic and immunological influences on growth. In: LAWRENCE, T.L.J.; FOWLER, V.R. (ed). Growth of farm animals. New York: CAB INTERNATIONAL,1997. p.102-149.

LUGER, D. et al. Association between weight gain, blood parameters, and thyroid hormones and the development of ascites syndrome in broiler chickens. Poultry Science, Champaing, v.80, p.965-971, 2001.

MARDER, J.; ARAD, Z. Panting and acid base regulation in heat stress birds. Comparative biochemistry and physiology, London, v.94, p.395-400, 1989.

MENDES, A.A. Rendimento e qualidade de carcaça de frangos de corte. In.: CONFERÊNCIA APINCO'2001 DE CIÊNCIA E TECNOLOGIA AVÍCOLAS, 2001, Campinas, SP. Anais... Campinas : Facta, 2001. V.3, 125p, p.3.

NATIONAL RESEARCH COUNCIL (NRC), Nutrient Requeriments of Poultry. 9.Rev. Ed. Washington D.C.:
National Research Council, National Academic, 1994. p.22-24.

SZABO, J. et al. Effect of malabsorption síndrome on pancreatic function in broilers. Poultry Science, Champaing, v.68, p.1553-1560, 1989.

YAHAV, S. et al. Effects of diurnally cycling versus constant temperatures on chicken growth and food intake. British Poultry Science, London, v.37, p.43-54, 1996.

YAHAV, S. et al. Thermoregulation in naked neck chickens subjected to different ambient temperatures. British Poultry Science, London, v.39, p.133-138, 1998.

YALÇIN, S. et al. Comparative evaluation of three commercial stocks in hot vs temperate climates. Poultry Science, Champaing, v.76, p.921-929, 1997.

WYLIE, L.M. et al. Effects of ambient temperature and restricted feeding on growth of feathers in growing turkeys. British Poultry Science, London, v.42, p.449-455, 2001.

WASBURN, K.W. et al. Relationship of strain variation and feed restriction to variation in blood pressure and response to heat stress. Poultry Science, Champaing v.59, p.1586-1588, 1980 . 